\title{
$\mathrm{PDA}$ 를 활용한 홍수예보시스템의 효율적 관리방안에 대한 연구
}

\author{
정 승 백 ${ }^{+}$양 승 인 ${ }^{++}$
}

요 약

\begin{abstract}
관측소의 기록저장 장치는 수위계와 우량계로부터 5 분 간격으로 측정된 데이터를 저장한다. 그리고 관측소의 RTU(Remote Terminal Unit) 는 $\mathrm{VHF}$ 와 위성통신을 이용하여 10 분 간격으로 홍수통제소의 $\mathrm{TM}$ (Telemetering)으로 측정된 데이터를 전송한다. 이때 전송되는 데이터는 레코 더에 저장된 전체 데이터가 아니라 10 분 간격으로 측정된 데이터이다. 홍수 통제소에서는 수신된 데이터를 홍수예보를 위해 분석한다. 또한 중 요한 점은 관측소의 유지보수이다. 본 논문에서는 홍수예보를 위한 효과적인 유지보수 시스템을 제안한다. 그것은 PDA의 CDMA와 Blutooth 기술을 사용하였다. 제안된 시스템은 휴대용이며 관측소에 저장된 데이터를 RTU없이 쉽게 홍수통제소로 전송할 수 있다. 또한 홍수통제소로 부터 전송 받아서 다른 지역의 관측소 데이터를 원격으로 볼 수 있다. 따라서 제안하는 시스템은 인력과 시간의 낭비를 줄여서 관측소의 유지 보수 업무를 효율적으로 할 수 있다.
\end{abstract}

키워드 : 홍수예보, PDA, CDMA, Bluetooth

\section{A Study on Effective Management Method of the Flood Forecast System using PDA}

\author{
Seungback Jung ${ }^{\dagger} \cdot$ Seung-In Yang ${ }^{\dagger+}$
}

\begin{abstract}
The recorder at observatory can save the measured data from water gauge and rain gauge at an interval of five minutes. And then, the RTU (Remote Terminal Unit) in observatory sends the measured data in the recorder to the TM (Telemetering) in FCO (Flood Control Office) at an interval of ten minutes using VHF or satellite communication. But the transmitted data is not the stored data at the recorder, it is just data that is measured at an interval of ten minutes. In the FCO , the transmitted data is analyzed in order to forecast the flood. And also one of the most important things is the maintenance of an observatory. In this paper, an effective management system for the flood forecast is proposed. It uses the CDMA and the Blutooth technology on PDA. The proposed system is very portable, and also easily able to send the data stored at the recorder in observatory to TM in FCO without RTU. And it allows us to view remotely the data of other observatories by downloading from the FCO. Hence the system can do efficiently the maintenance of observatory without wasting manpower and time.
\end{abstract}

Keywords: Flood Forecast, PDA, CDMA, Bluetooth

\section{1. 서 론}

최근 급격하게 변화하는 정보화 시대에 기후의 변화는 인 류의 삶을 매우 위협하는 수준으로 변화하고 있다. 또한 이 러한 기후 변화는 매우 급격하게 변화하고 있으며, 특히 우 리나라의 경우 지리적 요인으로 인하여 봄철에는 황사, 가

† 정 회 원 : 숭실대학교 정보통신전자공학부 박사후 연구원

†† 정 회 원: 숭실대학교 정보통신전자공학부교수(교신저자) 논문접수: 2009년 12월 29일

수 정 일 : 1 차 2010년 3월 29일, 2차 2010년 6월 14일 심사완료 : 2010년 6월 15일
뭄 그리고 여름철에 집중되는 폭우 및 태풍 등의 영향으로 인하여 빈번한 홍수 피해가 발생하고 있으며 이로 인한 인 명 피해 및 산업시설의 피해가 늘어나고 있는 추세이다. 이 러한 홍수 피해를 최소화하기 위하여 홍수 예보 시스템은 필수적으로 필요한 시스템이다. 홍수 예보를 위하여 각 하 천의 수위와 하천 주변의 우량을 파악하고 데이터베이스화 한 후 분석하는 것은, 홍수를 좀 더 정확하게 예보 및 경보 하는데 매우 중요한 일이다[1,2]. 또한 이러한 시스템을 정 기적으로 방문하여 신호의 송·수신 상태, 기록유닛의 정상작 동 등 시스템 유지보수는 필수적인 업무이다. 그러나 여러 
곳에 있는 하천과 각 관측소 등을 각각 방문하여 기기를 점 검하고 데이터를 백업 하는 것은 매우 어려운 일이다. 최근 모바일 통신에 대한 많은 연구가 이루어지고 있다. 특히 휴 대용 데이터 단말기인 $\mathrm{PDA}$ 를 이용한 다양한 시스템이 연구 되고 있다. $\mathrm{PDA}$ 시스템은 휴대가 가능한 작은 크기와 높은 데이터 처리율로 인하여 $\mathrm{PC}$ 나 노트북을 대신하여 주정차 관리[3], 원격 로봇 조정 등[4] 다양한 분야에서 사용되고 있 다 $[5,6]$. 그리고 CDMA, Bluetooth, Wireless LAN 등 다양 한 통신 인터페이스를 제공하고 있다. 특히 Bluetooth 기술 은 휴대용 기기에 사용되어 다양한 분야에서 연구 되고 있 다[7]. 본 논문에서는 홍수예보시스템의 효율적인 관리를 위 하여 PDA를 활용한 홍수 예보 시스템의 관리 시스템을 구 현하였다.

본 논문의 구성은 다음과 같다. 2장에서는 기존의 홍수예 보시스템의 관리시스템을 살펴보고 문제점을 도출하며, 3장 에서는 도출된 문제점을 해결하기 위한 방법을 제시하고 제 시된 방법으로 시스템을 구현하고 성능평가 한다. 그리고 마지막으로 4장에서는 결론을 맺는다.

\section{2. 홍수예보 관리 시스템}

효과적인 홍수 예보를 위해서는 각 하천의 정확한 수위와 하천 주변의 우량 데이터가 필요하다. 하천의 수위와 하천 주변의 우량을 파악하는 방법은 (그림 1)과 같이 각 하천에 관측소가 있으며 관측소와 연결된 우량계와 수위계가 있다. 이 우량계와 수위계를 이용하여 매 5분 간격(또는 사용자 설정시간 단위: 5 분, 10 분, 30 분)으로 우량과 하천의 수위를 관측소의 기록유닛에 저장한다. 그리고 RTU(Remote Terminal Unit)는 매 10 분 간격으로 측정된 데이터를 홍수 통제소의 TM (TeleMetering)으로 전송한다. 10분 주기로 전송하는 이유는 홍수통제소의 TM장비는 VHF통신을 하며, 이때 사 용하는 변조 방식은 FSK 방식을 사용한다. 따라서 여러 개 의 관측소와 동시에 통신하는 것이 불가능함으로 각각의 관 측소는 시간차이를 두고 전송하게 된다. 이때 전송되는 데
이터는 5 분 간격으로 저장된 모든 데이터가 아니고 전송당 시의 측정결과 한 개일 뿐이다. 이러한 무선 통신을 제공하 는 이유는 많은 관측소가 하천 주변에 설치되는데 지리적 특성상 전력 공급 및 통신선의 공급이 원활하지 못하여 태 양전지에 의한 전력 시스템을 사용하여 무인시스템으로 작 동한다. 따라서 관측소의 장비는 저 전력으로 작동하여야만 한다. 역시 마찬가지 이유로 유선 통신망을 구축하기가 쉽 지 않기 때문에 $\mathrm{VHF}$, 인공위성 등의 무선 통신만이 사용된 다. 이렇게 TM방식으로 전송된 데이터는 실시간으로 현장 에서 관측된 데이터이기 때문에 홍수 예보에 가장 중요한 데이터이다. 그러나 일반적인 수위 자료의 오류는 수위계등 기기 고장 또는 통신 장비의 고장으로 인한 오류가 대부분 이다. 이러한 오류를 미연에 방지하고 통제소의 데이터를 좀 더 정확히 유지하기 위하여 관측소의 관리 업무는 매우 중요한 업무이다. 관측소의 관리 업무는 통제소와 관측소간 의 통신상태 테스트, 기록유닛에 5 분 간격으로 저장된 데이 터의 백업, 그리고 관측소의 관리 업무 중 다른 관측소의 이상 발생 시 즉시 다른 관측소의 이상 유무를 확인하는 업 무로 이루어져 있다. 기존의 관리 시스템은 이러한 업무를 수행하는데 있어서 몇 가지 문제점이 있다. 우선 통제소와 관측소간의 통신 상태를 테스트는 방법은 통제소에서 송출 한 테스트 신호를 관측소에서 SNR (Signal to Noise Ratio) 를 측정한다. 이 업무를 위해서 관측소의 출장 직원은 통제 소의 직원에게 전화를 걸어 해당 관측소의 이름을 알려주고 테스트 신호의 송출을 요구한다. 이때 사용되는 신호는 Tone 신호와 Noise 신호를 사용한다. 이러한 업무 과정에서 통제소의 직원과 관측소 직원은 계속적으로 통화 상태를 유 지하고 있어야만 한다. 다음으로 기록 유닛에 저장된 매 5 분 간격의 데이터 백업 업무가 있다. 이 업무는 $\mathrm{VHF}$ 를 통 해서 10 분마다 전송되는 측정 데이터 외에 별도로 복사하여 좀 더 정확한 홍수예보를 위하여 홍수 예보 시스템에 입력 된다. 이 업무를 위해서는 관리직원의 노트북을 이용하여 기록유닛의 데이터를 복사한다. 이때 기록 유닛과 노트북은 RS-232프로토콜을 사용하여 유선으로 연결하게 된다. 출장

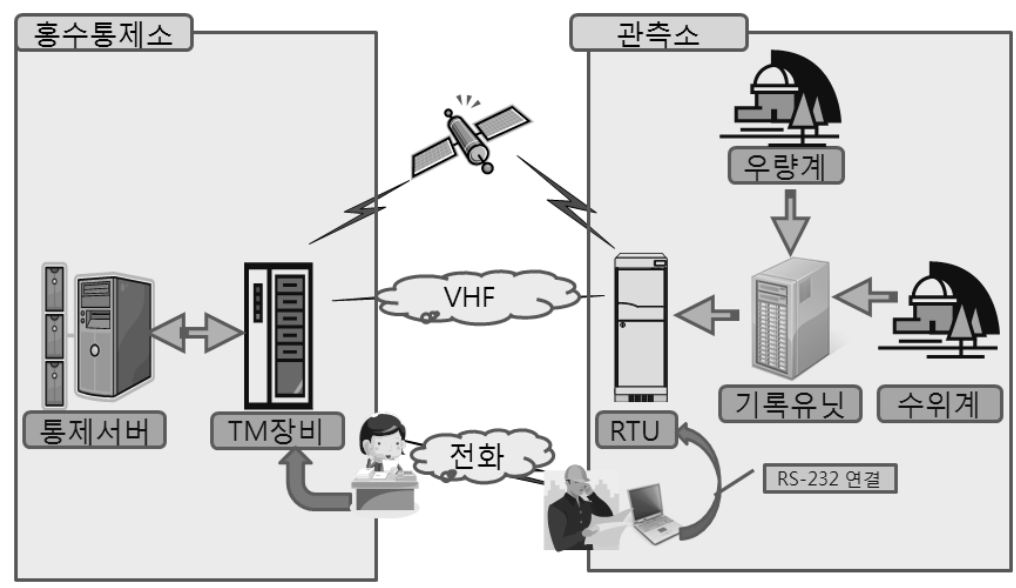

(그림 1) 홍수예보시스템 구성도 
직원은 항상 노트북과 $\mathrm{RS}-232$ 케이블을 소지하고 있어야 하 는 불편이 생긴다. 마지막으로 관측소 관리 업무 중에 다른 관측소에서 이상이 발생했을 경우 이상이 발생한 다른 관측 소에서 통제소로 전송한 데이터를 확인할 필요가 있다. 이 경우 출장 직원은 통제소 직원에게 전화로 데이터 확인을 요청하고 이상 유무를 통보 받게 된다. 그리고 이상이 발생 한 다른 관측소로 이동하거나 다음 관측소로 이동한 후 상 기의 작업을 반복한다. 그리고 모든 관리 업무가 끝나면 통 제소로 복귀하여 노트북에 복사된 각 관측소의 기록유닛의 데이터를 홍수예보 시스템으로 입력한 후 모든 관리 업무는 종결 된다. 이러한 업무수행 과정에서 다음과 같은 문제점 이 도출된다. 첫째, 관측소와 통제소에 각 1 명씩 최소한 두 명의 인력이 필요하다. 둘째는 노트북 기반의 관리시스템은 하루에 여러 군데의 관측소를 관리해야 하는 관리 직원에게 휴대성이 떨어진다. 그리고 노트북을 항시 휴대하기 위하여 전원 어댑터, $\mathrm{RS}-232$ 케이블 등의 보조 장치들이 필요하다. 그리고 출장 직원은 꼭 통제소로 복귀하여 복사한 데이터를 입력하여야 한다.

본 논문에서는 이러한 문제점을 해결하기 위하여 모바일 환경에서 사용가능한 홍수예보 시스템의 관리 시스템을 구 현하여 효율적으로 홍수예보시스템을 효율적으로 관리할 수 있는 방안을 제안하였다.

\section{PDA를 이용한 홍수예보 관리시스템}

기존의 홍수예보시스템을 위한 관리시스템은 노트북상에 구현되어 휴대성이 떨어지며, 무선 인터넷과 같은 무선 통 신을 지원하지 않기 때문에 홍수예보시스템의 관측소 관리 에 매우 어려움이 있었다. 본 논문에서는 이러한 문제점을 해결하기 위해서 $\mathrm{PDA}$ 를 활용하여 모바일 환경에서 관측소 관리 업무를 할 수 있는 시스템을 제안한다. 먼저 제안하는 시스템의 주요기능은 통제소의 직원과 출장 직원이 유기적 으로 협조해야 하는 통신상태 확인 업무와 타 관측소의 데 이터 확인 업무를 하기 위하여 통제소의 직원 도움 없이 출 장 직원 단독으로 업무를 해결할 수 있도록 하였다. 또한
RTU로부터 복사한 데이터를 PDA를 이용하여 통제소의 데 이터베이스에 직접 입력할 수 있게 하였으며, 다른 관측소 의 데이터를 조회할 수 있도록 하였다. 이러한 기능을 구현 하기 위해서 필요한 시스템 구성은 (그림 2)와 같다. (그림 2)에서 JAVA-Server 는 Client인 PDA와 Socket 으로 연결 되며 통제소의 TM 장비를 운영하는 Server 이다. 이러한 구성으로 인해서 통제소의 직원도움 없이 츨장 직원 단독으 로 관리 업무를 수행할 수 있다. 또한 RTU와의 연결은 Bluetooth를 이용한 무선통신을 사용하기 때문에 케이블 등 이 필요 없으므로 휴대성이 좋아 졌다. $\mathrm{PDA}$ 에서 Socket을 연결하기 위해서는 $\mathrm{PDA}$ 에 $\mathrm{CDMA}$ 기능이 있어야 한다. 또한 RTU와 Bluetooth로 연결되기 위해서는 Bluetooth 모듈을 탑재하고 있어야한다. 따라서 이러한 필요기능을 모두 지원 하는 (주)블루버드 사의 BM-200모델[8]을 사용하였다. 상기 $\mathrm{PDA}$ 는 마이크로소프트사의 Windows CE4.0을 사용한다. 그리고 $\mathrm{PDA}$ 의 작은 화면으로 인하여 사용자에게 데이터를 입력하는 항목을 최소한으로 줄였으며 대부분은 클릭에 의 해서 선택이 가능하도록 메뉴를 구성하여 사용자의 편의성 을 높였다.

\subsection{SNR 측정}

비상시 홍수통제소와 관측소 간의 정확한 데이터 송수신 을 위하여 평소 홍수통제소와 관측소 간의 신호의 질 즉 $\mathrm{SNR}$ 을 검사하는 것은 매우 중요한 일이다. 그러나 기존시 스템은 홍수 통제소 직원이 있어야지만 이러한 검사를 수행 할 수 있었다. 본 논문에서 제안하는 시스템에서는 PDA에 서 직접 테스트 신호를 요청하여 신호를 검사할 수 있도록 하였다.

(그림 3)의 (a)는 홍수통제소로 테스트 신호를 요청하는 화면이며 (b)는 요청한 신호가 정상적으로 수신 되었다는 화면이다. 테스트를 위한 신호는 톤 신호와 노이즈 신호 두 가지이며 이 두 가지의 신호 세기를 측정하여 관측소와 통 제소 사이의 신호상태를 테스트 할 수 있다. 이때 (그림 3) 의 (a)에서 유역을 선택 하는 것은 여러 하천에 있는 관측 소중 현재 위치한 하천을 지정하는 것이다.

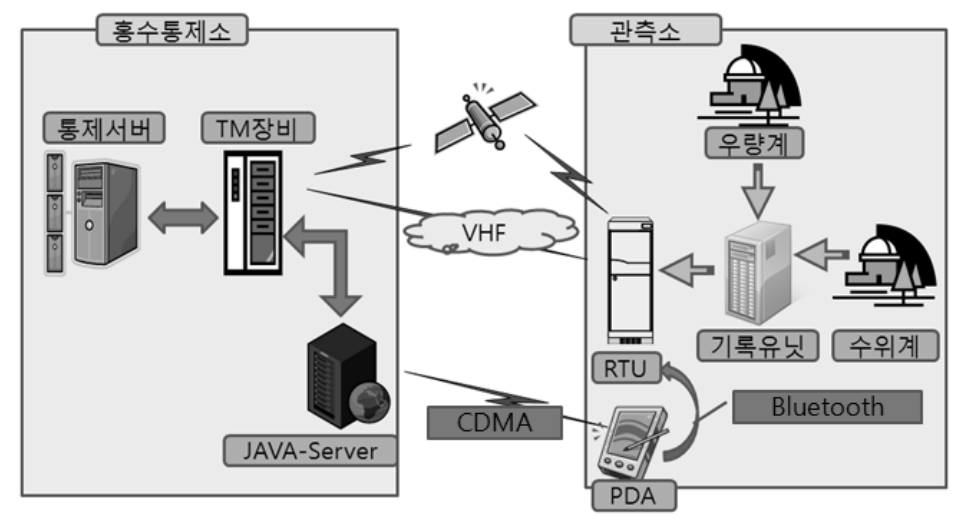

(그림 2) 제안하는 시스템의 구성도 


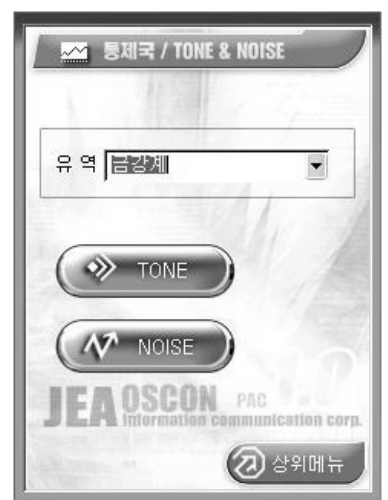

(a)신호 요청 화면

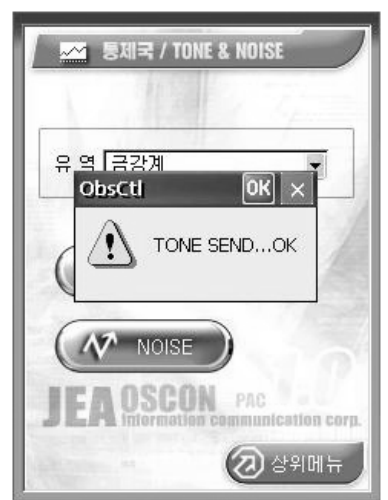

(b)신호 수신 확인

(그림 3) (a)신호 요청 화면 (b) 신호 수신 확인

\section{2 데이터 저장 및 전송}

관측소 관리 업무 중 하나인 해당 하천의 수위와 우량을 저장하는 것이다. 이는 정확한 홍수 예보를 위하여 매우 중 요한 일이다. 이러한 데이터는 수위계와 우량계로부터 매 5 분 간격으로 기록유닛에 저장되며 저장된 데이터는 출장 직 원이 정기적으로 방문하여 데이터의 이상 유무를 판별하고 복사하여야 한다. 기록유닛의 데이터를 복사하기 위해서는 RTU와 노트북을 RS-232 프로토콜을 사용하여 연결하여야 하며 이를 위해서 노트북과 케이블이 필요하다. 하루에 여 러 곳의 관측소를 관리해야 하기 때문에 매번 케이블을 설 치하고 조작하는 행위는 매우 번거롭고 업무의 효율이 떨어 진다. 그러나 본 논문에서 제안한 시스템은 $\mathrm{PDA}$ 기반이기 때문에 휴대성이 매우 좋다. 또한 RTU와의 연결을 RS-232 케이블이 아닌 Bluetooth를 이용한 근거리 통신방식을 사용 함으로써 추가적인 케이블 작업 없이도 원활한 업무 수행을 할 수 있다. 하지만 RS-232 프로토콜만 지원하는 기존에 설 치된 관측소의 RTU는 Bluetooth를 지원하지 않기 때문에 RS-232 to Bluetooth Converter를 사용한다. 이 Converter 는 배터리로 작동하며 소형이기 때문에 휴대성이 매우 좋 다. 따라서 기존에 케이블을 이용하여 작업 할 때 보다 업 무 효율이 좋아 진다. RTU로부터 PDA로 복사한 데이터는 CDMA를 이용한 Socket통신을 이용하여 관측소에서 직접 홍수 통제소의 홍수예보시스템의 DBMA에 전송할 수 있다. 이러한 기능은 출장 직원이 꼭 통제소로 복귀한 후 입력해 야 하는 업무의 비효율성을 개선한 것이다.

(그림 4)의 (a)는 제안한 시스템을 이용하여 기록 유닛에 저장된 데이터를 RTU를 통하여 $\mathrm{PDA}$ 로 복사하는 기능이다. 유역과 국명을 선택하고 수위 또는 우량을 선택한다. 그 전 송하고자 하는 시작 일시와 종료 일시를 선택하면 된다. 복 사된 데이터는 PDA의 외부 메모리에 "국명/수위 or 우량/ 시작일시.TXT"의 파일명으로 저장된다. 그 후 데이터를 홍 수예보시스템에 입력을 하고자 하면 (그림 4)의 (b)와 같이 유역과 파일명을 선택하여 전송할 수 있다.

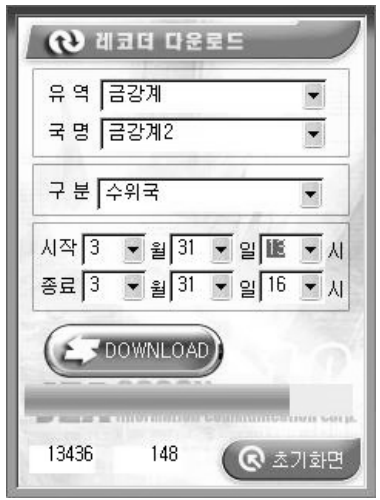

(a)RTU로부터 데이터를 백업하는 화면

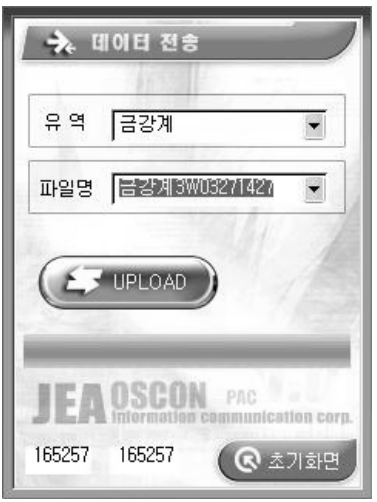

(b) 백업된 데이터를 DBMS로 전송하는 화면
(그림 4) RTU로부터 데이터를 백업하여 전송하는 화면

\section{3 제안시스템 성능시험}

제안하는 시스템 구현 후 테스트를 위하여 실제 전국 유 역에 설치되어 있는 관측소 중에 5 군데를 선정하여 직접 테스트하였다. 선정된 관측소 강경, 규암, 공주, 석화, 유성 등 이다. 이중 공주와 유성은 도심과 가까운 곳이며 다른 관측소는 도심과는 거리가 먼 산간 지방 등으로 나누어 선 정하였다. 이러한 선정 기준은 도심지역에서는 여러 가지 전파의 영향 등으로 인해 본 논문에서 제안하는 시스템의 영향이 있는지를 알아보려고 하였다. 또한 평가하기 위해 동행한 인원 전원이 기타 Bluetooth장치, 무선 랜 등 다양한 전자 장비를 제안하는 시스템의 근거리에서 작동하여 전파 의 간섭 여부 등을 종합적으로 판단하였다. (그림 5)는 성능 평가를 위한 관측소 중 한 곳의 전경이며 대부분의 관측소 가 이렇듯 도로에서 떨어진 곳에 위치해 있다. 따라서 우천 시에는 직원이 비를 맞고 관측소로 이동하여야 했지만 본 논문에서 제안하는 시스템을 이용할 경우 차량 안에서도 원 활한 작업이 가능함을 알 수 있었다. 단, 이때는 Bluetooth 통신이 가능한 근거리여야 한다. (그림 6)은 실제 관측소의 내부 전경이다. 관측소의 장비는 기록유닛, RTU, 무전기 그 리고 배터리 등으로 구성되어 있다. 성능평가를 위하여 기 록유닛의 최대 저장 크기인 일 년 동안의 수위, 우량 데이 터를 전송하였다. 일 년 동안의 데이터 크기는 약 $340 \mathrm{Kbyte}$ 이며 성능평가 결과 전반적으로 Bluetooth통신은 지역에 관 계없이 모두 원활하게 되었다. 이때 전송시간은 약 1 분 30 초 정도였다. 이렇게 전송속도가 느린 이유는 설치된 $\mathrm{RTU}$ 는 RS-232 프로토콜을 지원하고 있으며 이때 접속 속도는 $9600 \mathrm{bps}$ 로 매우 느린 속도이기 때문이다. 향후 제작되는 RTU는 Bluetooth를 기본 장착하여 제작하면 전송되는 속도 를 향상할 수 있을 것으로 생각 된다.

다음으로는 PDA를 이용하여 홍수통제 시스템과 Socket 통신을 테스트 하였다. 테스트 데이터는 동일하게 적용하였 다. 먼저 유성과 공주의 경우 도심지역이며 도심지역의 경 우 매우 빠른 속도로 전송되는 것을 확인 하였다. 제안하는 


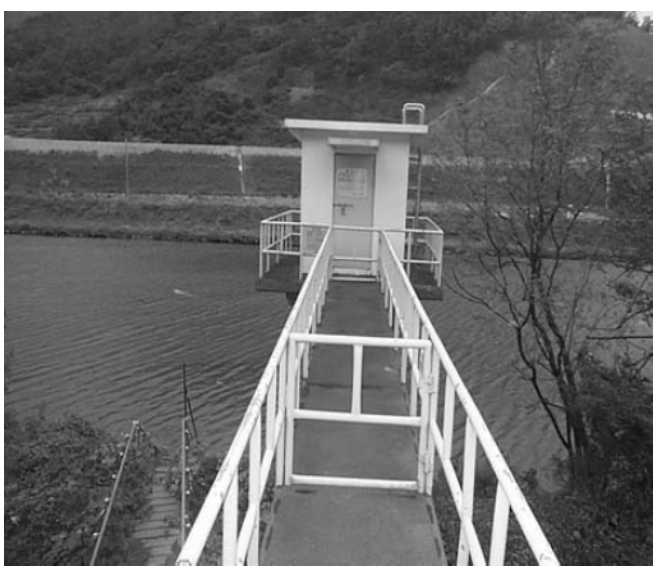

(그림 5) 성능평가를 위한 관측소 전경

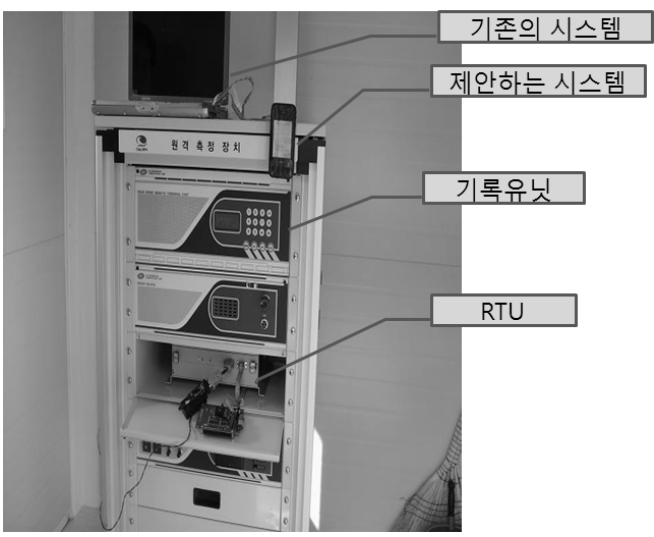

(그림 6) 제안된 시스템의 성능평가 모습

시스템은 통신비의 절감을 위해 전송 명령이 있을 경우만 $\mathrm{CDMA}$ 망에 연결하여 통신을 시작한다. 따라서 $\mathrm{CDMA}$ 를 이 용한 전송을 위해서 CDMA에 연결 후 홍수통제서의 JAVA -Server와 연결한다. 그리고 데이터 전송 후 연결 해지하는 과정을 거치게 된다. 평가에 사용한 $340 \mathrm{~KB}$ 의 데이터를 전 송하는데 걸린 시간은 약 3 초 정도로 매우 빠르게 전송되었 다. 그러나 강경, 규암, 석화 등 산간지방에서는 동일한 데이 터를 전송하는데 약 5 10초 정도의 전송시간을 보였다. 이 는 이동 통신사의 데이터망 자체가 도심에 치중하고 있는 것으로 생각되어진다. 그러나 통신이 안 되는 곳은 단 한군

〈표 1〉기존 시스템과의 비교

\begin{tabular}{|c|c|c|}
\hline & 기존 시스템 & 제안하는 시스템 \\
\hline SNR 측정 & $\mathrm{O}$ & $\mathrm{O}$ \\
\hline 데이터 저장 & $\mathrm{O}$ & $\mathrm{O}$ \\
\hline 무선 전송(CDMA) & $\mathrm{X}$ & $\mathrm{O}$ \\
\hline $\mathrm{RTU}$ 무선접속 & $\mathrm{X}$ & $\mathrm{O}$ \\
\hline 이동 중 전송 & $\mathrm{X}$ & $\mathrm{O}$ \\
\hline 데이터 확인 & $\mathrm{O}$ & $\mathrm{O}$ \\
\hline 관측소 제어 & $\mathrm{X}$ & $\mathrm{O}$ \\
\hline
\end{tabular}

데도 없었다. 다음의 <표 1>은 기존 시스템과 본 논문에서 제안하고 있는 시스템의 차이점을 보여준다.

\section{4. 결 론}

본 논문에서는 홍수예보시스템의 관리 업무를 위해 PDA 를 활용한 관리 시스템을 제안하였다. 제안된 시스템은 $\mathrm{PDA}$ 기반의 관리 시스템을 구현함으로써 관측소 출장 직원 단독으로 모든 업무가 가능해 짐으로 인해 높은 업무 효율 과 예산을 절감할 수 있게 되었다. 또한 다양한 무선 통신 인터페이스를 제공함으로 사용자의 편리성을 극대화 하였 다. 실험결과 다양한 위치에서도 통제소와 원활한 통신 접 속이 이루어 졌다. 그러나 기 설치된 관측소의 RTU는 Bluetooth 기능이 탑재되어있지 않아서 Converter 사용이 필요하다. 따라서 향후 제작되는 RTU의 경우는 Bluetooth 기능이 탑재 되어야 할 것이다. 만일 RTU에 Bluetooth 기 능이 탑재 된다면 RTU에서 $\mathrm{PDA}$ 로의 데이터 전송시간을 많이 줄일 수 있을 것이다. 본 논문에서는 홍수예보시스템 의 관리 업무를 위하여 $\mathrm{PDA}$ 를 활용한 관리 시스템을 제안 하였고 따라서 전체 업무의 처리 속도가 많이 향상되었으며 제안한 시스템을 통하여 좀 더 정확한 홍수 예·경보 시스템 을 구축하는데 일조 할 것으로 사료된다.

\section{참 고 문 헌}

[1] 이길성, 김영오, 박재현, “안양천 유역의 물순환 건전화 기술개 발", 과학기술부, 2005.

[2] 허철, “수문(水文)조사 선진화 5개년 계획”, 한국수자원학회지 : 물과미래 제38권 제5호 통권 제148호 (2005. 9) pp.16-22 $1738-9488$

[3] 윤해성, 궁상환, " $\mathrm{PDA}$ 를 이용한 불법주정차 단속시스템의 설 계 및 구현”, 제 27 회 한국정보처리학회 춘계학술발표대회 논 문집, 제 14권, 제 1 호, pp.577-580, 2007. 05.

[4] Ho Seoc Ahn, In-Kyu Sa, Jin Young Choi, "PDA-Based Mobile Robot System with Remote Monitoring for Home Environment," IEEE Transactions on Consumer Electronics, Vol.55, No.3, AUGUST 2009.3.

[5] 문승진, 이용주, "차량 충돌 사고에 대한 위치 확인 및 서비스 시스템”, 정보처리학회논문지A, v.16A, No.5, pp.381-388, 2009 년 10월.

[6] 안개일, 김기영, 서동일, “휴대용통신단말의 효과적인 보안관 리를 위한 보안 재구성기법의 설계 및 구현”, 정보처리학회논 문지C, v.16C, No.6, pp.691-698, 2009년 12월.

[7] Uichin Lee, Member, IEEE, Sewook Jung, Dae-Ki Cho, Alexander Chang, Junho Choi, and Mario Gerla, "P2P Content Distribution to Mobile Bluetooth Users," IEEE TRANSACTIONS ON VEHICULAR TECHNOLOGY, VOL. 59, NO. 1, JANUARY 2010.

[8] http://www.bluebird.co.kr/index.htm 


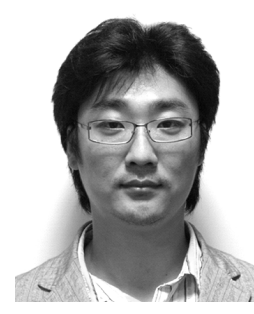

정 승 백

e-mail : begy@korea.com

2002년 한라대학교 컴퓨터공학과(학사)

2004년 숭실대학교 정보통신공학과(공학석사)

2004년 2009년 숭실대학교 전자공학과(공 학박사)

2009년 현 재 숭실대학교 정보통신전자 공학부 박사후 연구원

관심분야: 임베디드, 컴퓨터 구조, 초고주파 회로설계

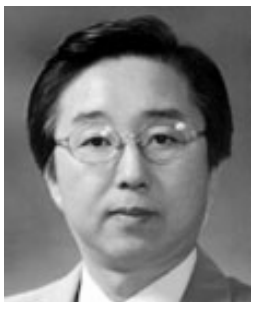

양 승 인

e-mail : siyang@ssu.ac.kr

1974년 서울대학교 전기공학과(공학사)

1976년 한국과학기술원 전기공학과(공학석사)

1987년 한국과학기술원 전기 및 전자공학과 (공학박사)

1978년 현 재 숭실대학교 정보통신전자 공학부교수

2004년 2005년 한국전자파학회 회장

2005년 현 재 한국전자파학회 명예회장

관심분야: 임베디드, 디지털시스템 